\title{
CARACTERIZAÇÃo DE ÁGUA DE PROCESSAMENTO DE INDÚSTRIA MAÇÃS
}

\author{
GAMBA, V. ${ }^{1}$, CARPES, V. M. ${ }^{2}$ e HEMKEMEIER, M. ${ }^{3}$ \\ ${ }^{1}$ Universidade de Passo Fundo, Faculdade de Engenharia Química. \\ ${ }^{2}$ Universidade de Passo Fundo, Programa de Pós Graduação em Ciência e Tecnologia de \\ Alimentos. \\ ${ }^{3}$ Universidade de Passo Fundo, Faculdade de Engenharia e Arquitetura. \\ E-mail para contato: 150817@upf.br
}

\begin{abstract}
RESUMO - As indústrias da cadeia produtiva de maçãs do Estado do RS utiliza elevada demanda de água para a higienização e transporte das frutas durante seu processamento. Quando utilizadas correntes hídricas para esse transporte, evita-se o manuseio e consequentemente a deformação das maçãs. Assim, a água utilizada no processo é considerada um ponto de controle imprescindível na indústria, já que esta água deve seguir padrões de potabilidade, conforme a legislação vigente, por estar em contato direto com as frutas. Todavia, o tempo de residência da água nos tanques e calhas durante o processo, varia de acordo com a presença de interferentes físicoquímicos e microbiológicas, que alteram diretamente a qualidade da água, bem como das frutas. Diante do exposto, o presente trabalho visou caracterizar a água de processamento de uma indústria de maçãs, quanto a concentração de poluentes que alteram a qualidade da mesma na planta industrial. Observou-se que os parâmetros utilizados para a caracterização das amostras apresentaram variações entre as coletas, pois são de amostras reais, e sofrem interferência e heterogeneidade durante o ciclo de uso.
\end{abstract}

\section{INTRODUÇÃO}

A demanda hídrica em indústrias, principalmente no ramo alimentício é justificada pela sua presença em diversas etapas do processamento. No caso em estudo, o uso de correntes hídricas é responsável não apenas pela higienização como também pelo transporte das maçãs por meio de calhas, a fim de evitar choques mecânicos provenientes de impactos, compressão, vibração, cortes e rachaduras que podem ocorrer durante a colheita e processo. E que representam um grave risco para a qualidade fisiológica, metabólica, sensorial e sanitária das maçãs, visto que por meio dessas lesões mecânicas pode haver a disseminação de doenças fúngicas.

A colheita das maçãs ocorre entre os meses de fevereiro a abril, em alguns casos se estende até o mês de maio (AGAPOMI, 2015; BNDES, 2010; SANHUEZA et al., 2003), e durante esse período, as maçãs colhidas são encaminhadas para a indústria, onde a logística da cadeia produtiva, favorece a contaminação da água de processo por poluentes e microrganismos que reduzem o ciclo de vida útil da água. 
Para minimizar os efeitos negativos do aspecto da água no decorrer dos processos, algumas indústrias de processamento de maçãs adotam sistemas convencionais de filtração e de desinfecção, usando cloro ativo. Contudo, esses sistemas de filtração são ineficientes para a remoção de material coloidal e de matéria orgânica natural, como substâncias húmicas (MATILAINEN; VEPSÄLÄINEN; SILLANPÄÄ，2010； SÄRKKÄ; VEPSÄLÄINEN; SILLANPÄ̈̈, 2015), que reagem quimicamente com o cloro ativo podendo levar a formação de substâncias cancerígenas (CHENG et al., 2003; SÄRKKÄ; VEPSÄLÄINEN; SILLANPÄ̈̈, 2015; WANG et al., 2016; WENG et al., 2006; XIAO et al., 2014).

Diante do exposto, o presente trabalho visou caracterizar a água de processamento de uma indústria de maçãs, quanto a concentração de poluentes que alteram a qualidade da mesma na planta industrial.

\subsection{Materiais e métodos}

A caracterização da água de processamento ocorreu por meio de sete coletas de amostras de água em uma indústria de processamento de maçãs, da cidade de Vacaria/RS, que utiliza $830 \mathrm{~m}^{3} /$ dia de água no processo industrial e o ciclo de vida útil varia em torno de uma semana.

As amostras foram coletadas e identificadas conforme a Quadro 1, e acondicionadas e refrigeradas até $4{ }^{\circ} \mathrm{C}$ (ABNT, 1987a; ABNT, 1987b). Para a caracterização das amostras de água foram realizadas análises físico-químicas que compreenderam os parâmetros de concentração dos seguintes poluentes: Demanda Química de Oxigênio (DQO), Sólidos Suspensos Totais (SST), turbidez e cor, sendo utilizado como referência padrão o "Standard Methods for the Examination of Water and Wastewater" (APHA, 2012). Já para a análise de Matéria Orgânica (MO) foi utilizado como referência padrão a NBR Nº 10739/1989 Determinação de oxigênio consumido por permanganato de potássio (ABNT, 1989). A análise microbiológica de contagem de bolores e leveduras, de acordo com métodos da Instrução Normativa nº. 62/2003 - MAPA (BRASIL, 2003).

Quadro 1 - Identificação das amostras

\begin{tabular}{|c|c|}
\hline Amostra & Mês de coleta \\
\hline 1 & Abril/2016 \\
\hline 2 & Maio/2016 \\
\hline 3 & Junho/2016 \\
\hline 4 & Agosto/2016 \\
\hline 5 & Setembro/2016 \\
\hline 6 & Novembro/2016 \\
\hline 7 & Dezembro/2016 \\
\hline
\end{tabular}

Fonte: Elaborado pelo Autor (2017).

\subsection{Caracterização}

As Tabelas 1 e 2 apresentam os dados referentes à caracterização das amostras. 
Tabela 1 - Caracterização físico-química

\begin{tabular}{cccccc}
\hline Amostra & $\begin{array}{c}\text { MO } \\
(\mathbf{m g} / \mathbf{L})\end{array}$ & $\begin{array}{c}\text { DQO } \\
(\mathbf{m g} / \mathbf{L})\end{array}$ & $\begin{array}{c}\text { SST } \\
(\mathbf{m g} / \mathbf{L})\end{array}$ & $\begin{array}{c}\text { Turbidez } \\
(\mathbf{N T U})\end{array}$ & $\begin{array}{c}\text { Cor } \\
(\text { Hanzen })\end{array}$ \\
\hline $\mathbf{1}$ & $4,36 \pm 0,42^{\mathrm{cd}}$ & $44,07 \pm 3,53^{\mathrm{c}}$ & $48,00 \pm 5,29^{\mathrm{cd}}$ & $26,33 \pm 1,15^{\mathrm{c}}$ & $22,67 \pm 0,58^{\mathrm{cd}}$ \\
$\mathbf{2}$ & $3,90 \pm 0,30^{\mathrm{d}}$ & $52,82 \pm 4,88^{\mathrm{c}}$ & $50,33 \pm 25,64^{\mathrm{c}}$ & $29,67 \pm 1,15^{\mathrm{c}}$ & $20,67 \pm 1,16^{\mathrm{d}}$ \\
$\mathbf{3}$ & $6,10 \pm 0,06^{\mathrm{cd}}$ & $48,79 \pm 1,47^{\mathrm{c}}$ & $61,33 \pm 1,54^{\mathrm{ab}}$ & $31,00 \pm 1,00^{\mathrm{c}}$ & $30,33 \pm 0,58^{\mathrm{c}}$ \\
$\mathbf{4}$ & $6,30 \pm 1,05^{\mathrm{c}}$ & $45,72 \pm 9,81^{\mathrm{c}}$ & $64,40 \pm 1,16^{\mathrm{a}}$ & $79,00 \pm 11,13^{\mathrm{b}}$ & $70,00 \pm 4,04^{\mathrm{b}}$ \\
$\mathbf{5}$ & $12,30 \pm 1,90^{\mathrm{b}}$ & $59,46 \pm 22,43^{\mathrm{bc}}$ & $32,00 \pm 4,38^{\mathrm{e}}$ & $64,00 \pm 8,32^{\mathrm{b}}$ & $63,00 \pm 6,42^{\mathrm{b}}$ \\
$\mathbf{6}$ & $19,90 \pm 1,13^{\mathrm{a}}$ & $88,19 \pm 1,42^{\mathrm{a}}$ & $53,00 \pm 4,24^{\mathrm{bc}}$ & $99,00 \pm 1,15^{\mathrm{a}}$ & $89,00 \pm 0,00^{\mathrm{a}}$ \\
$\mathbf{7}$ & $19,40 \pm 0,50^{\mathrm{a}}$ & $84,16 \pm 2,21^{\mathrm{ab}}$ & $41,00 \pm 1,41^{\mathrm{de}}$ & $76,00 \pm 1,15^{\mathrm{b}}$ & $68,00 \pm 1,73^{\mathrm{b}}$ \\
\hline
\end{tabular}

Resultados expressos como média de três determinações \pm desvio padrão. Valores seguidos de letras diferentes na mesma coluna diferem-se pelo Teste de Tukey $(\mathrm{p}<0,05)$.

Fonte: Elaborado pelo Autor (2017).

Tabela 2 - Caracterização microbiológica

\begin{tabular}{cc}
\hline Amostra & $\begin{array}{c}\text { Fungos - } \\
\text { Bolores e leveduras } \\
\text { (Log UFC/mL) }\end{array}$ \\
\hline $\mathbf{1}$ & N. A. \\
$\mathbf{2}$ & N. A. \\
$\mathbf{3}$ & $3,50 \pm 4,95^{\mathrm{c}}$ \\
$\mathbf{4}$ & $4,01 \pm 1,41^{\mathrm{a}}$ \\
$\mathbf{5}$ & $3,74 \pm 6,36^{\mathrm{b}}$ \\
$\mathbf{6}$ & $4,13 \pm 0,71^{\mathrm{a}}$ \\
$\mathbf{7}$ & $4,06 \pm 1,41^{\mathrm{a}}$ \\
\hline
\end{tabular}

Legenda: N.A. - Não Analisado.

Resultados expressos como média de três determinações \pm desvio padrão. Valores seguidos de letras diferentes na mesma coluna diferem-se pelo Teste de Tukey $(\mathrm{p}<0,05)$.

Fonte: Elaborado pelo Autor (2017).

Nota-se na Tabela 1 que pelo Teste de Tukey, os parâmetros de MO e cor seguiram uma tendência, indicando a MO está associada ao material em suspensão. Os parâmetros de DQO e turbidez também seguem uma tendência e possivelmente, os poluentes que atribuem turbidez à água em estudo, conferem também a elevação da concentração de DQO. A turbidez se deve à presença de partículas suspensas na água, com tamanho variando desde suspensões grosseiras até partículas coloidais (não sedimentáveis). Desse modo, a remoção de DQO está diretamente associada à remoção da concentração de material suspenso e coloidal na água.

Em relação ao parâmetro microbiológico de contagem de bolores e leveduras, descrito na Tabela 2 observa-se que as amostras apresentaram elevada contaminação fúngica, bem como, variação na caracterização das mesmas. Essa variação se deve aos diferentes períodos de coleta das amostras, pois os meses de colheita das maçãs variam de janeiro até o mês de 
abril, e no decorrer do ano as maçãs ficam armazenadas em câmaras frias para que sejam processadas de acordo com a necessidade do mercado (AGAPOMI, 2015; BNDES, 2010).

Conforme Sanhueza (2008), o risco de disseminação de contaminação fúngica durante o processamento das maçãs é alto, pois durante todo o processo é utilizado elevada demanda de água, que constitui um ambiente naturalmente propício para o crescimento de fungos, em razão de possuírem estratégias metabólicas que lhes permitem sobreviver em ambientes oligotróficos. Dessa forma, os fungos são transportados pela água do processo e contaminam as maçãs, acelerando seu processo de podridão, causando prejuízos para a indústria.

Pode-se observar na Tabela 2, que o período de maior contaminação fúngica varia entre os meses de agosto a dezembro, quando a maioria das frutas processadas é proveniente do armazenamento em câmaras frias (SANHUEZA, 2008; SANHUEZA et al., 2003).

\subsection{Conclusão}

Observou-se, a partir da caracterização da água, que há variação na concentração dos poluentes analisados, pois, as amostras apresentam heterogeneidade, por sofrerem interferência durante o ciclo de uso da água no processamento da indústria de maçãs. Dessa forma, a caracterização físico-química e microbiológica deve ser realizada a cada coleta, para que se possa determinar uma metodologia de tratamento de água adequada às características dos poluentes presentes, visto que, o tratamento convencional não é capaz de aumentar o ciclo de uso dessa água. Nos meses em que ocorre a colheita das maçãs e posterior processamento na indústria, os interferentes físico-químicos apresentam menores concentrações, devido os descartes hídricos serem mais frequêntes. Os meses que apresentam maiores contaminações fúngica e concentração de interferentes físico-químicos foram nos meses de agosto a dezembro, quando a maioria das frutas processadas é proveniente do armazenamento em câmaras frias para posterior distribuição no mercado consumidor.

\section{REFERÊNCIAS}

ABNT. Associação Brasileira de Normas Técnicas. NBR 9897: Planejamento de amostragem de efluentes líquidos e corpos receptores - Procedimento. Rio de Janeiro - RJ, 1987a.

ABNT. Associação Brasileira de Normas Técnicas. NBR 9898: Preservação e técnicas de amostragem de efluentes líquidos e corpos receptores- Procedimento. Rio de Janeiro - RJ, 1987b.

ABNT. Associação Brasileira de Normas Técnicas. NBR 10739: Água - Determinação de Oxigênio Consumido - Método do permanganato de potássio. Rio de Janeiro - RJ, 1989.

AGAPOMI. Associação Gaúcha dos Produtores de Maçã do Rio Grande do Sul. 2015. Disponível em: <http://agapomi.com.br/>. Acesso em: 29 de agosto de 2015.

APHA.AMERICAN PUBLIC HEALTH ASSOCIATION. Standard Methods for the Examination of Water and Wastewater. 22 ed. Washington: IWWA, 2012. 
BNDES. Banco Nacional do Desenvolvimento Econômico e Social. Informativo Técnico SEAGRI - Fruticultura: A Produção de Maçã no Brasil. Rio de Janeiro - RJ, nº . 2, novembro, 2010.

CHENG, M.L.; HO, H.-Y.; HUANG, Y.-W.; LU, F.-J.; CHIU, D. T.-Y. Humic acid induces oxidative DNA damage, growth retardation, and apoptosis in human primary fibroblasts. Experimental Biology and Medicine, v. 228(4), p. 413-423, 2003.

MATILAINEN, A.; VEPSÄLÄINEN, M.; SILLANPÄÄ, M. Natural organic matter removal by coagulation during drinking water treatment: A review. Advances in Colloid and Interface Science, v. 159, p. 189-197, 2010.

SANHUEZA, R. M. V. Controle de contaminação por fungos. Revista da Maçã, Fraiburgo SC, v. 2, n. 8, p. 16-18, 2008.

SANHUEZA, R. M.; CATTANIO, M. E. Controle biológico de Penicillium expansum em pós-colheita de maçãs 'Fuji'. Summa Phytopathologica, Piracicaba - SP, v. 29, p. 182-187, 2003.

SÄRKKÄ, H.; VEPSÄLÄINEN, M.; SILLANPÄ̈̈̈, K. Natural organic matter (NOM) removal by electrochemical methods - A review. Journal of Electroanalytical Chemistry, v. 755, p. 100-108, 2015.

XIAO, P.; XIAO, F.; ZHANG W.; ZHAO, B.; WANG, D. Insight into the combined colloidal-humic acid fouling on the hybrid coagulation microfiltration membrane process: The importance of aluminum. Colloids and Surfaces A: Physicochem. Eng. Aspects, v.461, p. 98-104, 2014.

WANG, X.; LI, B. Q.; ZHAI, H. L.; XIONG, M. Y.; LIU, W. An efficient approach to the quantitative analysis of humic acid in water. Food Chemistry, v. 190, p. 1033-1039, 2016.

WENG, Y. H; LIA, K. C.; CHAUNG-HSIEH, L. H.; HUANG, C. C. Removal of humic substances (HS) from water by electro-microfiltration (EMF). Water Research, v. 40, p. 1783-1794, 2006. 